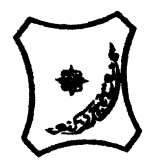

Bayero Journal of Pure and Applied Sciences, 10(1): 259 - 263

Received: May, 2016

Accepted: February, 2017

ISSN $2006-6996$

\title{
OCCURRENCE OF BOVINE MASTITIS AND ISOLATION OF Staphyloccocus SPECIES FROM FRESH COW MILK IN SETTLED FULANI HERDS IN KADUNA STATE, NIGERIA
}

\author{
Umaru, G. A. ${ }^{1,2 *}$, Kwaga, J. K. P. ${ }^{2}$, Bello, M. $^{2}$, Raji, M. A. ${ }^{3}$ and Maitala, Y. S. ${ }^{2}$ \\ ${ }^{1 *}$ Department of Animal Health, College of Agriculture, P.M.B.1025, Jalingo, Taraba State, Nigeria, \\ ${ }^{2}$ Faculty of Veterinary Medicine, Department of Veterinary Public Health and Preventive Medicine, Ahmadu Bello \\ University, Zaria, Nigeria. \\ ${ }^{3}$ Faculty of Veterinary Medicine, Department of Veterinary Microbiology, Ahmadu Bello University, Zaria, Nigeria. \\ * Corresponding Author E-mail: drghaliumaru@yahoo.com,drqabaka@gmail.com Tel: +2348036897535, \\ $+2347087767471$
}

\section{ABSTRACT}

A study was conducted on 360 dairy cows (1440 quarters) to determine the prevalence of mastitis by California Mastitis Test (CMT) and Staphylococci in settled Fulani herds in Kaduna State, Nigeria. The prevalence of mastitis at cow level was 26.9\% (97/360) and out of which 23.9\% (86/360) and $3.1 \%$ (11/360) were subclinical mastitis and clinical mastitis respectively. The prevalence at quarter level was 21.7\% (312/1440), and out of which 6.5\% (28/1440) was clinical mastitis and $19.7 \%$ (284/1440) was subclinical mastitis respectively. Statistical analysis showed that there was significant difference in the occurrence of mastitis among the age group $(P<0.05)$. The prevalence at quarter level was 25.2\% (157/624) in adult cows, 20.2\% (97/480) in young adults and 17.3\% (58/336) in old cows. Similar pattern of occurrence was recorded for both clinical and subclinical mastitis as the adults had $21.8 \%$ and $3.4 \%$, young adults had $19.8 \%$ and $0.4 \%$ and old cows had $15.8 \%$ and $1.5 \%$ respectively. The CMT scores showed that $55(64.0 \%)$ of the milk samples had a score of $1+, 26(30.2 \%)$ had a score of $2+, 3$ (3.5) had a score of $3+$ while only 2 (2.3\%) had a score of "Trace". Sixty seven (69.1\%) of the samples that were positive for CMT were found to be culture positive and out of which 56.7\% (55/97) were S. aureus and 12.3\% (12/97) were coagulase-negative staphylococci (CONS). The high prevalence of both clinical and subclinical mastitis coupled with the isolation of $S$. aureus and CONS are of great public health concern and requires strict control and preventive measures. The study recommends standards hygienic measures during milking and culling of infected cows to stop the spread of pathogens to uninfected cows.

Key words: mastitis, prevalence, Cow milk, Staphylococcus spp, settled Fulani herds, Kaduna State

\section{INTRODUCTION}

Dairy production systems provide milk that is rich in carbohydrates, fats, vitamins and minerals for the growing population (Wilson et al., 2004; Mekibib et al., 2010). However, milk production does not always meet the population's demands due to several factors, common among which is mastitis (Islam et al., 2010; Cervinkova et al., 2013; Kurjogi and Kaliwal, 2014). Mastitis is a complex and costly disease of dairy animals resulting from interplay between the dairy animal and the environment including the milking machines and milkers (Azmi et al., 2008). Mastitis is inflammation of mammary gland affecting all the species of domestic animals and characterized by the changes in physical appearance of milk, swelling, redness, and rises in temperature of udder (clinical mastitis) and in many case no visible changes in milk or udder (sub clinical mastitis) are apparent (Wilson et al., 2004; Samad, 2008; Reza et al., 2011; Kurjogi et al., 2014). Bovine mastitis has great economic impact on dairy industry and is associated with multi-etiologic agents, with one third of all dairy cows estimated to be infected with some form of mastitis in one or more quarters (Samad, 2008; Islam et al., 2010). In almost all dairy animals, microorganisms are mainly incriminated in mastitis, but some predisposing factors such as poor management and hygiene, teat injuries and faulty milking machines, pendulous udder with long teats, larger size of teat orifice in high yielding cows, etc. play an important role in the development of mastitis (Islam et al., 2010). Microorganisms causing mastitis are either contagious or environmental, with an infected udder serving as the primary reservoir of contagious pathogens whereas a contaminated environment as the primary reservoir of organisms causing environmental mastitis (Cervinkova et al., 2013). Streptococcus agalactiae, Staphylococcus aureus subsp. aureus and Mycoplasma spp. are the most typical contagious organisms causing mastitis (Suleiman et al., 2013; Cervinkova et al., 2013), 
while the environmental organisms are streptococci, Enterobacteriaceae and coagulase-negative staphylococci (CONS) (Bradley 2002; Barkema et al., 2009). Other organisms such as Pseudomonas spp., Pasteurellaceae, some pyogenic and anaerobic bacteria, yeasts and algae are also implicated in some cases of mastitis

Economic losses involving mastitis are mainly decrease in milk production, increased culling rate, cost involved with veterinary care and to a larger extent poor milk quality (Seegers et al., 2003; Rahman et al., 2009; Hashemi et al., 2011). Despite the economic importance associated with mastitis, it is not thoroughly investigated in Nigeria (Ameh et al., 1999; Junaidu et al., 2011).

Staphylococcus aureus is a major bacterium implicated with contagious bovine mastitis (Suleiman et al., 2013), that is difficult to prevent and control in the affected farms. Therefore, identification of $S$. aureus from mastitic milk is necessary for the control and prevention of this disease. This study is aimed at evaluating the prevalence of mastitis in cows by California Mastitis Test (CMT) and also isolating Staphylococci as the causative agent in Kaduna State, Nigeria.

\section{MATERIALS AND METHODS \\ Sample collection}

The study was conducted in Kaduna State, Nigeria. Cohort study was formed by identifying and selecting five (5) herds from each of the six (6) selected Local Government Areas namely: Kaduna South, Igabi, Lere, Sabon-Gari, Giwa and Zaria. Twelve (12) milk samples were collected from each of five (5) cohort herds making a total of sixty (60) from each Local Government Area. Thus a total of 400 milk samples were collected during the study period. All the samples collected were placed on ice and transported to the Bacterial Zoonoses laboratory, Faculty of Veterinary Medicine, Ahmadu Bello University, Zaria for standard laboratory procedures.

Clinical and subclinical mastitis test by California Mastitis Test (CMT)

The age of the cows were determined by dentition and confirmed by owners as Young adults (3-6 yrs), adults (7-10 yrs) and old (> $10 \mathrm{yrs}$ ) (Mekibib et al., 2010). Clinical mastitis was assessed by observing the udder visually and by palpation for visible trauma, tick infestation, pain, warmth and swelling of the super mammary gland (Mekibib et al., 2010). Abnormality in milk characteristics like blood tinged milk, watery secretions, clots and pus were checked (Dingwell et al. (2003).

Cows that did not have clinical mastitis were subjected to further examination for subclinical mastitis by using California Mastitis Test (CMT) as described by Dingwell et al. (2003).

Foremilk from each quarter was milked into cups of four-cup plastic paddle. The paddle was tilted to equalize milk quantities in the cups at $2.5 \mathrm{ml}$ each. Equal volume of the CMT reagent (Kruuse, Denmark) was added to each cup. The paddle was rotated to mix thoroughly. Changes in colour and gel formation were observed within 10-15 seconds after mixing and then scored depending upon the amount of gel formation as follows:

No reaction $=$ Negative

Appearance of streaks visible during rotation of the plate $=$ Trace

Distinct thickening during rotation, but no gel= $1+$

Slight formation of gel which follows the rotating plate very slowly $=2+$

Solid formation of gel that adheres to the base of the plate $=3+$

\section{Isolation of Staphylococcus aureus}

One (1) $\mathrm{ml}$ of milk was enriched in $10 \mathrm{ml}$ Tryptone Soya Broth (TSB, Oxoid) containing 6.5\% sodium chloride. Enrichment cultures and milk samples was then inoculated on to the surface of the Baird Parker medium supplemented with egg yolk and potassium tellurite, and incubated aerobically for 24 hours at $37^{\circ}$ C (Tamagnini et al., 2006; O' Brien et al., 2009). The $S$. aureus isolates were identified using colony morphology, Gram's staining, catalase, coagulase, motility, DNase and haemolysis tests (Normano, 2005; Tagmanini et al., 2006) and further confirmed using Microbact $^{\mathrm{TM}}$ Staphylococcal identification system 12S (Oxoid, Basingstoke, UK).

\section{Statistical analysis}

The prevalence of subclinical and clinical mastitis was calculated using the following formula:

Prevalence $(\%) \quad=$ Number of animals positive Number of animals tested $\quad \times 100 \%$

The data was statistically analyzed using SPSS package (Version 16.0). Chi-square and Fisher's Exact Tests at $5 \%$ level of confidence were used to determine the level of significant. A P value of $P<$ 0.05 was considered as significant.

\section{RESULTS}

The results obtained from the study are presented in Tables 1-4. The prevalence of mastitis at cow level was $26.9 \%(97 / 360)$ and out of which $3.1 \%(11 / 360)$ and $23.9 \%(86 / 360)$ were clinical and subclinical mastitis (Table 1). The prevalence of mastitis at quarter level was $21.7 \%$ (312/1440), and out of which $6.5 \%(28 / 1440)$ was clinical mastitis and $19.7 \%(284 / 1440)$ was subclinical mastitis respectively (Table 4 ). Statistical analysis showed that there was significant difference in the occurrence of mastitis among the age group $(P<0.05)$. The prevalence at quarter level was $25.2 \%(157 / 624)$ in adult cows, $20.2 \%(97 / 480)$ in young adults and $17.3 \%$ (58/360 in old cows (Table 4). Similar pattern of occurrence was recorded for both clinical and subclinical mastitis as the adults had rates of $21.8 \%$ and $3.4 \%$, young adults had $19.8 \%$ and $0.4 \%$ and old cows had $15.8 \%$ and $1.5 \%$ respectively.

Samples from Igabi, Lere and Kaduna South had the highest rates of mastitis $(35.0 \%, 31.7 \%$ and $30.0 \%)$ than those from Zaria (26.7\%), Giwa $(25.0 \%)$ and Sabon-Gari (13.3\%), but all occurred at a significant rate $(P<0.05)$. Similar pattern of occurrence was observed with both clinical and subclinical mastitis as samples from Igabi had the highest prevalence of $30.0 \%$, 
Bajopas Volume 10 Number 1 June, 2017

followed by Kaduna South and Zaria with $26.7 \%$ each, while the least was Sabon-Gari with $13.3 \%$. In contrast, clinical mastitis was highest in Lere (6.7\%) and lowest in Giwa (3.3\%) and Kaduna South (3.3) respectively. No case of clinical mastitis was recorded in Sabon-Gari and Zaria.

The CMT results showed that $55(15.3 \%)$ of the milk samples had a score of $1+, 26(7.2 \%)$ had a score of $2+, 3(0.8)$ had a score of $3+$ while only $2(0.6 \%)$ had a score of "Trace" (Table 2).

Sixty seven samples $(69.1 \%)$ of the mastitis positive samples were found to be culture positive and out of which $44.2 \%$ (43/97) were $S$. aureus and $24.7 \%$ (24/97) were coagulase negative staphylococci (Table 3 ). The prevalence of both $\mathrm{S}$. aureus and coagulase negative staphylococci (CONS) was significantly higher $(\mathrm{P}<0.05)$ in subclinical mastitis $(35.1 \%$ and $21.6 \%)$ than in clinical mastitis $(9.3 \%$ and $3.1 \%)$ respectively (Table 3 ).

Table 1: PREVALENCE OF CLINICAL AND SUBCLINICAL MASTITIS IN KADUNA STATE, NIGERIA

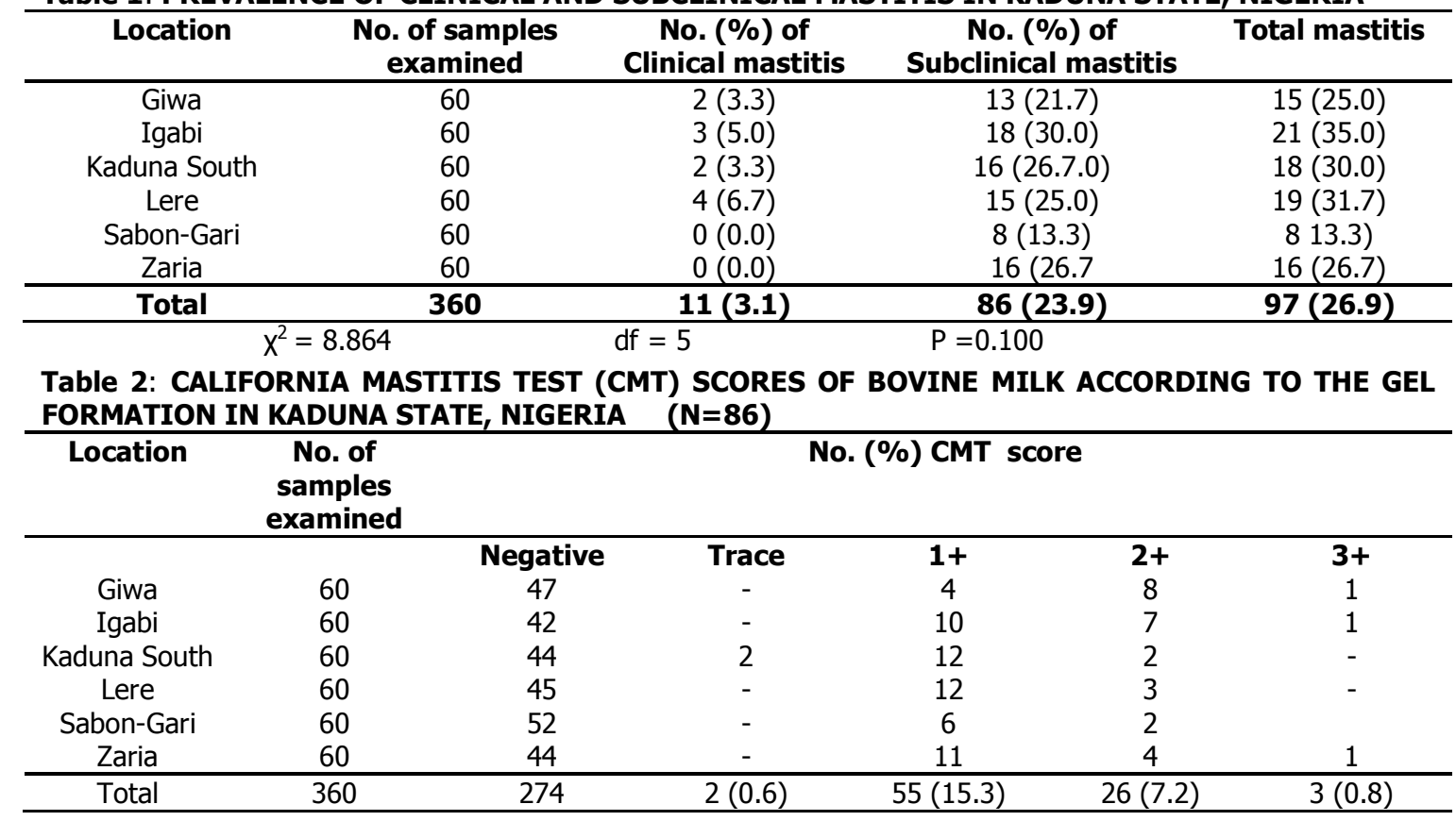

Table 3: PREVALENCE OF STAPHYLOCOCCI IN THE MASTITIC MILK IN KADUNA STATE, NIGERIA

\begin{tabular}{|c|c|c|c|c|c|}
\hline Mastitis & No. (\%) positive & \multicolumn{2}{|c|}{$\begin{array}{c}\text { No. (\%) S. aureus } \\
(\mathrm{N}=55)\end{array}$} & No. (\%) CONS & Total \\
\hline Clinical & $11(2.8)$ & \multicolumn{2}{|c|}{$9(20.0)$} & $3(3.1)$ & $12(17.9)$ \\
\hline Subclinical & $86(21.5)$ & \multicolumn{2}{|c|}{$34(58.2)$} & $21(21.6)$ & $55(82.1)$ \\
\hline Total & $97(24.3)$ & \multicolumn{2}{|c|}{$43(44.4)$} & $24(24.7)$ & $67(69.1)$ \\
\hline \multicolumn{6}{|c|}{$\begin{array}{l}\text { Key: CONS= Coagulase negative staphylococci } \\
\begin{array}{l}X^{2}=12.211 \\
\text { Table 4: OCCURRENCE OF MASTITIS ACCORDING TO THE QUARTERS AND AGE OF THE COWS }\end{array}\end{array}$} \\
\hline Age & $\begin{array}{c}\begin{array}{c}\text { No. of cows/ } \\
\text { quarters }\end{array} \\
\end{array}$ & \multicolumn{2}{|c|}{$\begin{array}{l}\text { No. (\%) clinical } \\
\text { mastitis }\end{array}$} & $\begin{array}{c}\text { No. (\%) subclinical } \\
\text { mastitis }\end{array}$ & Total \\
\hline Young adults & $120 / 480$ & \multicolumn{2}{|c|}{$2(0.4)^{a}$} & $95(19.8)^{a}$ & $97(20.2)$ \\
\hline Adults & $156 / 624$ & \multicolumn{2}{|l|}{$21(3.4)^{b}$} & $136(21.8)^{b}$ & $157(25.2)$ \\
\hline Old & $84 / 336$ & \multicolumn{2}{|l|}{$5(1.5)^{c}$} & $53(15.8)^{c}$ & $58(17.3)$ \\
\hline Total & $360 / 1440$ & \multicolumn{2}{|c|}{$28(1.9)^{d}$} & $284(19.7)^{d}$ & $312(21.7)$ \\
\hline \multicolumn{6}{|c|}{ Values in the same row with different superscript differ significantly $(P<0.05)$} \\
\hline \multicolumn{3}{|c|}{$\begin{array}{l}\text { DISCUSSION } \\
\text { The present study was carried out on settled Fulani } \\
\text { herds in Kaduna State to determine status of mastitis } \\
\text { in cow/quarters by California Mastitis test (CMT) and } \\
\text { microbiological analysis of both suspected and } \\
\text { apparently healthy milk samples for Staphylococcus } \\
\text { spp. The prevalence of clinical mastitis at cow level } \\
\text { was } 26.9 \%(n=97) \text { (Table } 1) \text {, the prevalence of }\end{array}$} & \multicolumn{3}{|c|}{$\begin{array}{l}\text { subclinical mastitis as detected by CMT was } 23.9 \% \\
\text { while that of the clinical mastitis is } 3.1 \% \text { (Table } 1 \text { ). } \\
\text { The prevalence in the present study is lower than the } \\
52 \% \text { reported by Junaidu et al. ( } 2011 \text { ) in Sokoto, } \\
\text { Nigeria, } 85.33 \% \text { by Shittu et al. (2012) in the } \\
\text { Savannah region of Nigeria, } 30.9 \% \text { by Suleiman et al. } \\
\text { (2013) in Plateau Sate, Nigeria and } 71.0 \% \text { by Mekibib } \\
\text { et al. (2010) in Ethiopia. }\end{array}$} \\
\hline
\end{tabular}


However, the result is higher than $2.1 \%$ reported by Ameh et al. (1999) in Maiduguri, Borno State, Nigeria and those reported elsewhere $(19.9 \%, 2.12 \%$ and $21.6 \%)$ respectively in Bangladesh, Sirajganj and Iran) (Rahman et al., 2009; Islam et al., 2010; Hashemi et al., 2011) The discrepancies in the figures recorded above could be due to differences in the management systems, stage of lactation, parity and breed of the dairy animals (Hashemi et al., 2011).

The overall quarter prevalence of mastitis in the present study was $21.7 \%(312 / 1440)$ with $6.5 \%$ (28/1440) as clinical mastitis and $19.7 \%(284 / 1440)$ as subclinical mastitis respectively. This is comparable with the reports of Ameh et al. (1999), but differ with the $44.9 \%$ and $43.25 \%$ overall quarter prevalence reported by Mekibib et al. (2010) and Shittu et al. (2012) in Holeta town, Central Ethiopia and Savannah region of Nigeria respectively.

The traditional method and protocol of milking cows was the method practiced in all the herds sampled, thus milking hygiene was generally poor in the majority of the farms sampled. Mastitis and infection preventive measures like the use of udder antisepsis, hand disinfectants, post-milking teat dipping, dry cow therapy and intensive surveillance were also not practiced in these herds. This may be the possible reasons for the high prevalence of mastitis in these areas. Another reason could be the traditional practice of keeping calves away from the dam for long periods and only allowed to suckle for a short period coupled with low milk supply that resulted in the calves suckling vigorously leading to teat injuries, which subsequently predisposed to infection (Junaidu et al., 2011).

In this study, the prevalence of subclinical mastitis $(21.5 \%)$ was higher than clinical mastitis $(2.8 \%)$ as observed by many authors (Ameh et al., 1999; Rahman et al., 2009; Mekibib et al., 2010; Islam et al., 2010; Hashemi et al., 2011; Suleiman et al., 2013). The possible explanation is that subclinical mastitis is characterized by gross visible pathologies which are familiar to the farmers and so are treated as soon as noticed. It was also shown that subclinical mastitis is normally found to be higher than clinical mastitis due to host's defense mechanism that reduces the severity of the disease (Mekibib et al., 2010). The CMT results showed that $55(64.0 \%)$ of the milk samples had a score of $1+, 26(30.2 \%)$ had a score of $2+, 3$ (3.5) had a score of $3+$, while only 2 $(2.3 \%)$ had a score of "Trace" (Table 2$)$. This agrees with the acceptable fact that the CMT score of $1+$ which corresponds to somatic cell count SCC of 500, 000 is the threshold index of intra mammary infection (IMI).

Statistical analysis showed that there is significant difference in the occurrence of mastitis among the age groups $(\mathrm{P}<0.05)$. The prevalence at quarter level was $25.2 \%$ (157/624) in adult cows, $20.2 \%$ (97/480) in young adults and $17.3 \%$ (58/3360 in old cows (Table 4). Similar pattern of occurrence was recorded for both clinical and subclinical mastitis as the adults had $21.8 \%$ and $3.4 \%$, young adults had $19.8 \%$ and $0.4 \%$ and old cows had $15.8 \%$ and $1.5 \%$ respectively. This trend is in line with the reports by Ameh et al. (1999) who recorded high occurrence of mastitis in adults cows $(n=50)$ than in young cows $(n=25)$ and old $(n=8)$. Mekibib et al. (2010) also showed that the likelihood of mastitis in adult cows was more than in young adults. They reported the prevalence to be $56.0 \%$ in adults, $33.5 \%$ in young adults and $7.3 \%$ in old cows. It was observed that there was increase in cases of mastitis (clinical and subclinical) with advancing age. This is evident in the present study as the prevalence of mastitis increased from young adults to adult cows and decreased when the cows were old.

Even though, other pathogens were not examined, laboratory results showed that Staphylococcus aureus and coagulase negative staphylococci (CONS) were implicated as causes of mastitis in this study. Sixty seven $(69.1 \%)$ of the CMT positive samples were found to be culture positive and out of which $56.7 \%$ $(55 / 97)$ were $S$. aureus and $12.3 \%$ (12/97) were coagulase negative staphylococci (Table 3 ). Ameh et al. (1999) showed that coagulase negative staphylococci and $S$. aureus occurred predominantly in both clinical and sub-clinical bovine mastitis. In this study, $56.7 \%$ and $12.3 \%$ of $S$. aureus and CONS were respectively isolated from the 97 mastitic milk. This indicates that $69.0 \%$ of the mastitis was caused by staphylococci. This may also mean that staphylococci are not the only bacterial agents responsible for both clinical and subclinical mastitis in this study, hence other pathogens and agents were likely responsible for the remaining $31.0 \%$. This result is of public health concern due to the involvement of $S$. aureus in food poisoning outbreaks. The study is also in agreement with Mekibib et al. (2010) who revealed that $S$. aureus and CONS were the predominant bacteria isolated in mastitic milk in Ethiopia with a $47.1 \%$ and $30.1 \%$ prevalence rates respectively. A report by Suleiman et al. (2013) showed the prevalence of $S$. aureus in bovine mastitic milk to be $98.1 \%$ in Plateau State, Nigeria and suggested that most of the $S$. aureus were of human origin since $S$. aureus of animal origin coagulate bovine plasma, produce beta-hemolysis and are less often enterotoxigenic than the human isolates.

\section{Conclusion and recommendations}

The high prevalence of both clinical and subclinical mastitis coupled with the isolation of $S$. aureus and CONS are of great public health concern and requires strict control and preventive measures. Also, cows with mastitis as evident in this study would lead to decrease in the yield of high quality milk, thereby affecting nutritional demands of the populace. This has also an economic consequence for the famer as the milk would not be readily marketable. Therefore, farmers should adhere to good hygienic procedures during milking and proper management practices in order to reduced or eliminate infection of dairy cows. Culling of chronically infected cows is also recommended to avoid spread of pathogens to uninfected ones. All milk should be pasteurized before consumption or processing into other milk products to avoid transmission of pathogenic bacteria to humans through milk or milk products.

\section{Conflict of Interests}

We declare that there are no conflicting interests as regard to this research work. 


\section{Authors' contributions}

Umaru, G. A. designed and conducted the research work; Kwaga, J. K. P., Bello, M. and Raji, M. A. supervised the research work, participated in drafting the manuscript and final acceptance, while Maitala, Y. S. provided the technical assistance. The manuscript

\section{REFERENCES}

Ameh, J. A., Edgbe-Nwiyi, T. and Zaria, L. T. (1999). Prevalence of bovine mastitis in Maiduguri Borno State, Nigeria. VETERINARSKI ARHIV, 69 (2): 87-95.

Azmi, D. Hawari, F. and Dabbas, A. (2008): Prevalence and distribution of mastitis pathogens and their resistance against antimicrobial agents in dairy cows in Jordan. American Journal of Animal and Veterinary Sciences, 3 (1): 36-39.

Barkeme, H. W., Green, M. J., Bradley, A. J. and Zadoks, R. N. (2009). Invited review: the role of contagious disease in udder health. Journal of dairy Science, 92: 4717-4729.

Bradley, A. J. (2002). Bovine mastitis: an evolving disease. Veterinary Journal, 164: 116-128.

Cervinkova, D., Vlkova, H., Borodacova, I., Makovcova, J., Babak, V., Lorencova, A., Vrtkova, I., Marosevic, D. and Jaglic, Z. (2013). Prevalence of mastitis pathogens in milk from clinically healthy cows. Veterinarni Medicina, 58 (11): 567-575.

Dinwell, R. T., Leslie, K. E., Schukken, Y. H., Sargent, Y. H. and Timms, L. L. (2003). Evaluation of the California mastitis test to detect an intramammary infection with a major pathogen in early lactations dairy cows. Canadian Veterinary Journal, 44: 413-416.

Hashemi, M. Kafi, M. and Safdarian, M. (2011). The prevalence of clinical and subclinical mastitis in dairy cows in the Central Region of Fars Province, South of Iran. Iranian Journal of Veterinary Research, Shiraz University, 12 (3): $236-241$.

Islam, M. A., Rahman, A. K. M. A., Rony, S. A. and Islam, M. S. (2010). Prevalence and risk factors of mastitis in lactating dairy cows at Baghabari Milk Shed Area of Sirajganj. Bangladesh Journal of Veterinary Medicine, $\mathbf{8}$ (2): 157-162.

Junaidu, A. U., Salihu, M. D., Tambuwala, F. M., Magaji, A. A. and Jaafaru, S. (2011). Prevalence of Mastitis in Lactating Cows in some selected Commercial Dairy Farms in Sokoto Metropolis. Advances in Applied Science Research, 2 (2): 290-294.

Kurjogi, M. M. and Kaliwal, B. B. (2014). Epidemiology of Bovine Mastitis in Cows of Dharwad District. International Scholarly Research Notices, Available from: http://dx.doi.org/10.1155/2014/968076. was read and accepted by all authors prior to submission for publication.

\section{Acknowledgement}

We thank Dr. Ishak Bello (MD), the staff of MILCOPAL Dairy Company, Kaduna, Mallam Mahmud and all the Fulani herds' men for their support and co-operation during the study.

Mekibib, B., Furgasa, M., Abunna, F., Megersa, B. and Regassa, A. (2010). Bovine Mastitis: Prevalence, Risk Factors and Major Pathogens in Dairy Farms of Holeta Town, Central Ethiopia. $\quad$ Veterinary World, 3 (9): 397-403

Normanno, G. A., (2005). Coagulase positive staphylococci and Staphylococcus aureus in food products marketed in Italy. International Journal of Food Microbiology, 9: 73-79

Rahman, M. A., Bhuiyan, M. M. U., Kama, M. M. and Shamsuddin, M. (2009). Prevalence and risk factors of mastitis in dairy cows. The Bangladesh Veterinarian, 26 (2): 54-60.

Reza, V. H., Mehran, F. M. S., Majid, M. and Hamid, M. (2011). Bacterial pathogens of intramammary infections in Azeri buffaloes of Iran and their antibiogram. African Journal of Agricultural Research, 6 (11): 2516-2521.

Saad, M. A. (2008). Animal Husbandry and Veterinary Science, volume II, LEP pub no.11, Bangladesh Agricultural University campus, Mymensingh. Pp.1184-1189.

Seegers, H., Fourichon, C. and Beaudeau, F. (2003). Production effects related to mastitis and mastitis economics in dairy cattle herds. Veterinary Research, 34 (5): 475-491.

Shittu, A., Abdullahi, J., Jibril, A., Mohammed, A. A. and Fasina, F. O. (2012).Sub-clinical mastitis and associated risk factors on lactating cows in the Savannah Region of Nigeria. BMC Veterinary Research, 8: 134-142

Suleiman, A, B., Umoh, V. J., Kwaga, J. K. P. and Shaibu, S. J. (2013). Enterotoxigenic and antibiotic resistance of Staphylococcus aureus isolated from sub-clinical bovine mastitis in Plateau State, Nigeria. Research Journal of Microbiology, 8 (2): 101-107.

Tamagnini, L. M., Sousa, G. B. Gonzalez, R. D. and Bude, C. A. (2006). Microbial characteristics of crottin goat cheese made in different seasons. Small Ruminant Research, 66: 1745-180

Wilson, D. J., Gonzalez, R. N., Hert, J. A., Schulte, H., Bennett, G., Schukken, Y. and Groohn, Y. (2004). Effect of Clinical Mastitis On The Lactation Curve: A Mixed Model Estimation Using Daily Milk Weight. Journal of Dairy Science, 87: 2073-2084. 